\title{
Erratum to: The effect of pulsed harvesting policy on the inshore-offshore fishery model with the impulsive diffusion
}

\author{
Zhong Zhao • Xiuquan Zhang • Lansun Chen
}

Published online: 3 April 2010

(C) Springer Science+Business Media B.V. 2010

\section{Erratum to: Nonlinear Dyn \\ DOI 10.1007/s11071-009-9527-7}

The original version of this article unfortunately contained a mistake. The spelling of the second author's, was incorrectly given as Xuiquan Zhang. The correct name of the author is Xiuquan Zhang.

Springer apologizes for this error.

The online version of the original article can be found under doi:10.1007/s11071-009-9527-7.

Z. Zhao $(\bowtie) \cdot$ X. Zhang

Department of Mathematics, Huanghuai University,

Zhumadian, Henan 463000, P.R. China

e-mail: zhaozhong8899@163.com

Z. Zhao $\cdot$ L. Chen

Department of Applied Mathematics, Dalian University of Technology, Dalian 116024, P.R. China 